\title{
Reporting Unwanted Sexual Behavior at a Post-Secondary Institution: Student Understandings of Campus Policy
}

\author{
Lindsay Ostridge and Christopher D. O’Connor
}

\begin{abstract}
The Ontario government recently mandated all universities and colleges in Ontario, Canada to create a sexual violence policy that involves student input. Using a small commuter university in southwestern Ontario as a case study, this article examined student perceptions of an existing university sexual violence policy. More specifically, we conducted online qualitative research with seventeen students using an open-ended inductive, exploratory instrument. We asked students to read and define aspects of their university's sexual violence policy in their own words. The objective of this research was to examine if students adequately comprehended the language of the policy, how to report, who to report to, feel safe reporting, and whether or not they find the reporting process supportive of their needs. Also discussed are student recommendations for what they would like to see in university sexual violence policies.
\end{abstract}

Keywords: policy, sexual assault, campus sexual assault, sexual violence, Canada

Lindsay Ostridge, Ph.D. Candidate, Institute of Feminist and Gender Studies, Faculty of Social Sciences, University of Ottawa

Christopher D. O'Connor, Assistant Professor, Faculty of Social Science and Humanities, University of Ontario Institute of Technology, Oshawa, Ontario 


\section{Introduction}

In Canada, young women and LGBTQA continue to experience high rates of sexual violence, as demonstrated by the \#Metoo movement (CWF, n.d.). Given that many young women and LGTBQA pursue post-secondary education, campus sexual violence is something that postsecondary institutions need to address. Unfortunately, the reporting of campus sexual violence remains low (Sheehy \& Gilbert, 2015). Also, recent incidents at Canadian post-secondary institutions (e.g., mishandled reports, rape chants, and the discouraging of formal reporting) highlight the need for more focused attention on this issue. Currently, there are no national standards for addressing sexual violence on Canadian post-secondary campuses. Aside from some recent provincial legislation in Ontario and British Columbia, post-secondary institutions are responsible for their response to campus sexual violence (Ammar, Frederick, Marques, O'Connor \& Scott, 2016; Gunraj, Wandio, METRAC \& Canadian Electronic Library, 2015; Sheehy \& Gilbert, 2015). Overall, there are limited research on-campus response protocols in Canada or on how students themselves understand campus sexual violence policies (Ammar et al., 2016).

In this article, we examined student understandings of the sexual violence policy at a small, diverse, commuter university in southwestern Ontario, Canada. We also asked participants to provide recommendations for improving campus response protocols. In what follows, we first discuss structured action theory and the literature on policy response to sexual violence at postsecondary institutions. Second, the methods section discusses the online open-ended qualitative survey tool used to collect student's understandings. Next, we present the findings on student policy definition comprehension, student barriers to reporting, and student recommendations for improving sexual violence policy. Finally, drawing on structured action theory and student understandings, we argue that it is essential to incorporate student voices into the campus sexual violence policy-making process.

\section{Structured Action Theory}

Embodied hegemonic masculinity affords some men superior power with economic, political, social, and cultural privileges. Within this hierarchy, white heterosexual male interests tend to come first, creating rigid roles for gender, race and class. This structuring creates a false norm, producing a political and social rationale for subordinating femininities (embodied in both male and female bodies). Gendered actions are performative, exercised by men and women on an ongoing basis. The social construction of gender creates actions that are acceptable and unacceptable for each gender (Messerschmidt, 2000; 2016; 2018).

While gender is salient in the act of sexual violence, sexual violence also involves patterned forms of interaction among class, sexuality, and gender relations that are reproduced by actors to produce structured actions. These structures act together to create an environment that advantages the dominant group through actions, opportunities and privilege (Messerschmidt, 2000). The following sections explain the structures that create structured action.

Power exists for the individual or group that sets the economic, social, political and cultural agenda. With the use of this power, a person, group or institution can deny the authority of others 
by denying employment, denying police and protection services, and denying inclusivity into the powerful (dominant) group. This power interacts within and between groups (Messerschmidt, 1993; 2016). In terms of the campus environment, power can be seen within a sexual violence policy as policymakers at post-secondary institutions set the agenda for how they plan to respond, or not respond, to sexual violence on campus.

A hierarchy of sexual values and practices is another dimension where discrimination can occur. Dynamic with the cultural definitions of respectability, society judges sexual forms and practices, setting limitations and prohibitions to what is deemed acceptable in terms of partners, activities, and objects used in sexual activity. Due to cultural stereotypes, society perceives some women as objects, and some women as inherently rape able. Women are sexualized, some more than others, depending on their race and class (Collins, 2000; Messerschmidt, 2000; 2016).

Those who embody femininity are often sexualized and expected to display themselves as sexual beings. For rape victims, this often translates into them being described as temptresses or as hunted sexual prey (Benedict, 2005). Similarly, the media often help to uphold this inequality by describing sexual violence as pleasurable, comedic and using words such as fondled, caressed, attractive, and flirtatious rather than describing it as torture (Benedict, 2005).

This attitude is a reflection of the rape culture that we live in, which confuses the perception of harm and permits sexual violence against women and LGBTQA (Buchwald, Fletcher, \& Roth, 2005b). As a result, women and LGBTQA experience adverse sexual comments, forceful sexual touching, and the threat and act of forced sex (Buchwald, Fletcher \& Roth, 2005a). For example, this rape culture was clearly on display at the University of Ottawa and Dalhousie University School of Dentistry, where students created private male-only Facebook groups and posted about raping their female peers (Iyer, McRae, \& Backhouse, 2015; Report of the task force, 2016). Similarly, rape chants during frosh week at Saint Mary's University and the University of British Columbia (UBC Investigates, 2013) are another example. It is these above described structured actions that help explain how various pillars in society act together to allow sexual violence to occur on campus.

\section{Policy Responses to Sexual Violence on Campus}

While rare in Canada, mandated sexual assault policy directives are nothing new to the United States (Sheehy \& Gilbert, 2015). In particular, the Jeanne Clery Disclosure of Campus Security Policy and Campus Crime Statistics Act (Clery Act) requires that all post-secondary schools receiving federal financial aid report crimes that occur on or near their campuses. Also, Title IX of the Education Amendments of 1972 requires any educational institution that receives federal assistance to refrain from discriminating based on gender or face penalties from the federal government (U.S. Department of Education, Office for Civil Rights, 2013). Title IX also stipulates that a trained individual must be appointed to handle all reports of sexual violence. Further, postsecondary institutions are provided with a list of recommendations and best practices as well as a series of protocols that are expected to be followed when dealing with sexual violence (Amar, Stout, Simpson, Cardiello, \& Beckford, 2014; Sheehy \& Gilbert, 2015; U.S. Department of Education, Office for Civil Rights, 2013). Canada has no such legislation, and most complaint procedures are secretive and hard to find (Ammar et al., 2016; DeKeseredy \& Schwartz, 1998; Gunraj et al., 2015). 
Mandated policies are not without their flaws. For example, many argue that mandated policies unnecessarily add pressure to poorly equipped post-secondary institutions to adjudicate sexual assaults. Those involved in the disciplinary process are "typically not lawyers or trained fact-finders, and they are not familiar with either basic due process norms or with some of the victim-blaming features of sexual assault law that have been addressed to some extent in the criminal context" (Silbaugh, 2015, p.1050). Moreover, Sheehy and Gilbert (2015, p.17) note that "there is a perverse incentive for universities to discourage reporting so as not to go public with sexual assault on campus, and so it is vital that women be told that sexual violence is a criminal matter and are offered support in contacting police should they wish." Without regular auditing and significant fines, universities and colleges will fail to comply with reporting accurate incidents of sexual violence on campus (Sheehy \& Gilbert, 2015; Yung, 2015)

In regard to campus sexual violence responses and protocols in the United States, Amar et al. (2014) found that many institutions used an interdisciplinary team approach. For example, a sexual assault response team (SART) is typically used and comprised of health care, mental health, law enforcement, and victim advocate service providers. However, SART does not have established protocols to guide them with each response (Amar et al., 2014). While there is limited Canadian research on this topic, Ammar et al. (2016) found that there were two models in place at Ontario post-secondary institutions. The first was survivor-led, where the survivor is empowered to make decisions throughout the reporting procedure while the second was an automatic referral of sexual violence incidents to the police.

Overall, the research conducted thus far suggests that sexual violence policies at postsecondary institutions have been mostly ineffective. In particular, Osborne (1992) argues that these policies are ineffective because they do not address the underlying issues of misogyny occurring on campuses. Some policies even failed to include a definition of sexual assault or outline the rights of the complainant. In part, the reluctance of women and LGBTQA to report sexual violence to post-secondary institutions has been attributed to these institutions being male-dominated and producing policies that duplicate male power and control (Brubaker, 2009). Also, many policies are ineffective because they fail to ensure that the people in charge of the process had specialized training in responding to sexual violence (Ammar et al., 2016; Gunraj et al., 2015; U.S. Department of Education, Office for Civil Rights, 2013).

Survivors of sexual violence continue to experience a multitude of barriers to reporting their experiences to campus officials. These barriers can include self-blame, guilt, embarrassment, fear, as well as concerns about gossip, retaliation, and discrimination from their peers. Since the members of the campus environment engage in victim-blaming, survivors are often concerned about confidentiality (Amar et al., 2014; Brubaker, 2009; Fisher, Cullen, \& Turner, 2000; Tamborra \& Narchet, 2011; Walsh, Banyard, Moynihan, Ward, \& Cohn, 2010). For the most part, many students are not comfortable reporting incidents of sexual violence to campus officials. For example, female students note feeling uncomfortable reporting an incident to campus police due to curmudgeonly male officers (Tamborra et al., 2011). Further, many female students have not reported incidents because they believe campus services were ill-equipped to handle the discrimination they would face from peers. Also, many survivors chose not to report because they did not want to compromise their independence and be required to participate in adjudication (Campbell-Ruggard \& Van Ryswyk, 2001; Tamborra \& Narchet, 2011). 
Administrators have noted that not mandating a complainant's presence at a hearing is beneficial as it allows the survivor to feel more comfortable reporting. Most institutions in the United States offer confidential reporting and the use of a closed hearing board of faculty, staff, and students for investigations and sanctions. However, bringing a case forward before a board does eliminate confidentiality within the group and the complainant can be at risk of experiencing re-victimization (Amar, Stout, Simpson, Cardiello, \& Beckford, 2014; Karjane, Fisher \& Cullen, 2005). In Canada, mediation often is used as an alternative to the adjudication process. Disciplinary actions can include everything from a written reprimand to expulsion (Sheehy \& Gilbert, 2015). Alternatively, mediation can be inappropriate for sexual violence complaints due to power imbalances, pressures on the survivor, and the potential of exposing a survivor to self-doubt (California Sexual Assault Task Force, 2004; Cook, 2010; Gunraj et al., 2015; Lancaster \& Waryold, 2008). It can also allow administrators at post-secondary institutions to prioritize protecting the institution's reputation and enrollment numbers, rather than the survivor (Browne, 2014; Iyer, McRae, \& Backhouse, 2015).

Given the above-discussed issues, there is much work that needs to be completed if postsecondary institutions are to improve their policies and, thus, responses to sexual violence. Of particular relevance for this article is the importance of obtaining student feedback on barriers to reporting. When creating sexual assault policies, Tamborra et al. (2011) note that students are the most critical stakeholder. Further, it is essential to include student feedback as the policy must be read and understood by the student population. Policies should be comprehensive, provide actions that are easy to follow, and policy language should be accessible and understandable by the campus community, including students with disabilities (Gunraj et al., 2015; Osborne, 1992). Thus, policies "need to be thought of as a continuously evolving process and that policies and procedures governing responses to sexual violence on campus will require focused attention, critique, and revision" (Ammar et al., 2016, p.35).

This article aims to examine how students understand their university's sexual violence policy and the process of reporting sexual violence on campus. The work of DeKeseredy and Kelly (1993), DeKeseredy and Schwartz (1998), DeKeseredy, Schwartz, and Tait (1993), Dekeseredy, Schwartz, \& Alvi (2000), Newton-Taylor, DeWit and Gliksman (1998), and Senn, et al. (2014) are some of the only peer-reviewed research on campus sexual assault in the Canadian context. These authors did not investigate students' understandings of campus policies and responses regarding sexual violence. We are aware of only one other study (i.e., Tamborra and Narchet, 2011) that have examined student understandings of campus sexual assault at post-secondary institutions. This study did not investigate students' perceptions of campus sexual violence policies, which is what our research contributes to the literature on this topic.

\section{Methods}

This case study investigates a mid-size post-secondary institution situated in Ontario, Canada. This campus consists of two locations, about 20 minutes apart from each other, known as the Downtown Campus and the North Campus. The student population includes over 10,000 students. It is considered a commuter post-secondary institution with students from a variety of 
socioeconomic backgrounds, as well as rural, suburban, and urban areas. Most students have considerable family and work commitments and tend to be the first in their family to attend a postsecondary institution. As well, the student body is culturally and ethnically diverse, with a high proportion of LGBTQA and Indigenous students. These varied demographics in the student population provide an opportunity to hear from a diverse set of voices.

Utilizing a case study approach permits an intensive analysis of students' understandings of sexual violence within a post-secondary school setting. This approach allows us to be attentive to the types of responses given since there is only one institution and context. A case study permits depth in understanding of both the context and processes that surround the research question. Also, the case study approach provides concrete, context-dependent evidence that helps develop a theory that can be explanatory and predictive. It can also help to provide a foundation for conducting further investigations (Flyvbjerg, 2011). Since there is a lack of research on how students understand sexual violence policies on campus, this article and the measures used to collect data should be considered exploratory.

To examine student understandings, we developed an online qualitative survey using a constructionist grounded theory approach. This study aimed to ask students the 'what' and 'how' questions regarding their understandings of sexual assault policy. The goal was to examine whether or not students understood the policy and what they thought their actions would be, based on the policy (Charmaz, 2008; Denzin \& Lincoln, 2011a; Silbey, 2003). This inductive, exploratory method of research included having participants read the policy and then define key terms such as sexual assault, consent, and sexual violence. Other questions included whether or not the participant would report if a sexual assault happened to them, who they would report it to, would they feel comfortable or confident in reporting, what their fears are with reporting, was there anything that would prevent them from reporting, and was the process as outlined supportive. Specific questions in the survey also asked students to make recommendations to improve policy and campus safety.

Feminist qualitative researchers use this type of exploratory methodology to investigate topics such as sexual violence. Traditional methods of empirical research that have embedded regimes of power may replicate the barriers and oppressive structures that this research aims to resolve (Olesen, 2011). Therefore, we developed the open-ended qualitative instrument with the principles outlined by Charmaz (2008) which include: the understanding that every research project is a social construction, scrutinizing every decision within this project, improving methodological and analytical strategies throughout the process, and collecting enough data to be able to construct the participant's world. To do so, we gave the participants unlimited time and space to enter their thoughts and feelings with no contact or influence from researchers (Denzin \& Lincoln, 2011b).

We recruited participants through posters placed on campus bulletin boards. The poster listed details of the study with a link to the online instrument. The anonymous survey was open to all students aged 18 years or older, and we offered no compensation to participants. The survey took approximately 20 minutes to complete, and 17 participants completed the survey. Of the participants, $71 \%(\mathrm{n}=12)$ identified as female and 29\% $(\mathrm{n}=5)$ as male. The participants' ages ranged from 21 to 32 years old. There were a variety of self-reported ethnicities, including Caucasian ( $\mathrm{n}=5)$, South Asian $(\mathrm{n}=1)$, East Asian $(\mathrm{n}=1)$, Palestinian $(\mathrm{n}=1)$, African $(\mathrm{n}=1)$, Canadian 
$(\mathrm{n}=1)$, Canadian-Korean $(\mathrm{n}=1)$, Jewish $(\mathrm{n}=1)$, Black/White $(\mathrm{n}=1)$, Bi-racial $(\mathrm{n}=1)$ and Mixed $(n=1)$. The self-reported sexual orientation of the group was $65 \%(n=11)$ heterosexual, $6 \%(n=1)$ lesbian, and $18 \%(n=3)$ bisexual. The remaining participants did not answer the question. The current relationship status of the respondents was $41 \%(n=7)$ single, $47 \%(n=8)$ dating but not living together, and $6 \%(\mathrm{n}=1)$ cohabitating. We gave all the participants a pseudonym that was randomly assigned.

Our data analysis consisted of a narrative analysis developed by Doucet and Mauthner (2008) called The Listening Guide. This approach allows for both critical and constructed subjects and consists of multiple readings of the qualitative data. During each reading, the goal was to listen in a different way, focusing on a specific element (Doucet \& Mauthner, 2008). The elements consisted of reading for relational, and reflexivity constituted narratives, tracing narrated subjects, relational narrated subjects, and structured subjects. The first reading, we asked the question, "What is happening here?" We paid close attention to words, themes, characters, events, and plots (Doucet \& Mauthner, 2008). The second reading of the text attended to the narrator, investigating how they wrote about themselves and the social world. As language is key to the formation of subjectivity, we paid close attention to words and meaning (Kincheloe, McLaren, \& Steinburg, 2011), while also listening to what participants were saying and what they were trying to say (Doucet \& Mauthner, 2008). We identified themes as well as missing items (e.g., anal penetration when coding for the definition of sexual assault). The third reading focused on participants' social networks and intimate relations to get an understanding of the subject within these networks and with others. Our fourth reading focused on structured power relations and dominant ideologies within the narrative of the text. This last reading was essential as it revealed the macro-level narratives that the subjects find themselves in (Doucet \& Mauthner, 2008). After each reading, we made notes that are compiled in the results section.

\section{Results}

We have organized the results into three sections. The first section discusses students' level of comprehension of specific terms of the policy: sexual assault, consent, and sexual violence. The second section discusses students' perceived barriers to reporting. Finally, the third section addresses the students' recommendations for policy improvement and a safer campus environment.

\section{Comprehension of Key Terms}

Sections of the policy that listed definitions of sexual assault, consent, and sexual violence were provided to the participants to read. Participants were then asked to write their interpretation of the definition in their own words in an open-ended answer format. The definition of sexual assault provided by the institution was extensive and included all the main points as defined by the Criminal Code of Canada. It was lengthy, and perhaps too lengthy, as students seemed to find it difficult to relay the same level of detail in their answers. For instance, none of the students' responses included that sexual assault is a criminal offence under the Criminal Code of Canada. This information appears in the first sentence of the definition. 
Moreover, one person noted that sexual assault is an abuse of power, but the remainder of students did not. Although most students included 'unwanted' sexual activity in their definition, less than half of the group mentioned rape or penetration. Very few people expressly noted anal penetration in their interpretation of sexual assault. Less than half of the students indicated the various levels of severity of sexual assault. Overall, it appears that the general idea of sexual assault was understood, but not necessarily the specifics.

Encouragingly, more than half of the students mentioned a lack of consent in their definition of sexual assault. When defining consent in their own words, students' answers were generally shorter and more succinct than their answers about sexual assault. This finding is interesting, given that the consent policy definition provided by the institution was at least double the length of the sexual assault definition. Participants discussed consent as a voluntary affirmation to agree to engage in sexual activity. Words used by participants to express consent were permission, agreement, confirmation, indication, and an expressed affirmation to the act in question. Participants also noted that consent must be explicit, declared, outspoken, clear, and voluntary. Several students noted that "implied consent is not consent" (Shannon), even though the policy definition does not include implied consent. These responses may suggest that students had consent education prior to this study. Also, a quarter of the students stated that a woman could not consent when incapacitated, and just under half noted that consent must be verbal. Most importantly, the items missing from the student's definitions but found in the policy included: consent is limited to current experiences, consent cannot be predicated on a lie, consent cannot be given through coercion, and consent only exists between adults. Again, as there is quite a lot of information missing from the consent definition provided by students, this may suggest that the institution's policy definition of consent is too long or too complicated for students to fully grasp, or there is a lack of education that needs to support this definition.

In defining sexual violence, participants seemed confused, suggesting that this was a more difficult term to define. For example, Rachel noted that the definition in the policy was "[a] little unclear, but it is a violence that can also be based on gender, sexual orientation, and other social locations. That definition was not clear enough". Most students only noted that sexual violence was an act that caused harm, and that is violent and sexual. Most students failed to include gender, gender identity, or sexual orientation. Only a few students included psychological harm and discrimination in their definitions. Again, the general idea of sexual violence was understood, but the specifics were not. Overall, the students did show a general understanding of sexual assault, consent, and sexual violence, as written in the policy. Nevertheless, their responses often lacked detail. For example, students missed certain items such as the violation of the Criminal Code, anal penetration, or abuse of power, which is worrisome.

\section{Barriers to Reporting}

After reading the institution's policy on sexual violence, we asked participants whether they would report an incident of sexual assault; if they felt comfortable, confident, and safe reporting, whom they would report to, and why they would not report if they chose not to. The students' responses included the actions they would take to report, as well as fears and 
apprehensions about reporting to university authorities. Most participants stated that they would report a sexual assault if it happened to them. The majority of answers included reporting specifically to campus services such as campus security, administration, outreach services, or an equity and wellness specialist. Less than half mentioned contacting their local police services, even fewer mentioned family and friends, and one person mentioned a lawyer.

Some responses were more detailed than others and helped provide an understanding of how students viewed the reporting process. For instance, some made a distinction between an incident happening on-campus versus off-campus. For example, Vikki stated she would report to "[c]ampus security/safety if on campus, police if off-campus (but I probably wouldn't report anything to the police that doesn't have enough grounds for proof because I know how ridiculous the process can be)." Others viewed people close to them as well as local police services as a more legitimate place to report the incident than personnel on campus. For example, Chris stated:

Initially, I would probably report it to my friends and family. Afterward, I would promptly report it to the police. I do not think I would report it to the school right away... The only time when I would report something to the school first and not the police is if I do not think the matter was significant enough for the police -meaning, I was not sure if it was sexual assault. I have this belief that the police can do everything the campus police can, but more legitimately.

Overall, these responses help to illustrate the thought processes of a survivor confronted with the decision of reporting. Trust in, and competence of the people receiving the report appears to be key to encouraging reporting. Participants' responses also highlight the difficult position survivors are often put in to provide proof when reporting incidents.

Turning more specifically to reporting on campus, students generally had only a vague idea of who they would report to at the institution. The only exception was Rachel, who knew who she would report to, which was likely due to her experiencing the process directly. In terms of the level of comfort in reporting, most students stated they would feel confident/comfortable reporting to campus officials. Many of the students revealed the need to report as a way of healing. For example:

I would feel worse if I were to keep it in and be silenced. Even if I am unable to get administrative justice, procedural justice would suffice. Reporting an incident would also make me feel better because it would allow me to vent out my frustrations and hurt (Chris).

Similarly, Hannah noted that reporting was a way for her to regain her life without feeling fear. A minority of participants said that they would not feel confident or comfortable reporting but would report.

Students' feelings of safety while reporting garnered similar results. Many students stated that they would feel safe but were unsure about the steps that authorities would take as well as the reactions of the perpetrator and their peers. For example, Lisa mentioned needing anonymity to feel safe, "If I could remain anonymous, I would feel safe - If not, I would not feel as safe, 
especially if nothing is done about it." Many students mentioned that the reaction of the reporting officer was very important to their feelings of safety. If there was a favourable interaction, reporting was made more accessible. If not, the student would feel hesitant to report again.

There were a few students who stated that they would not feel safe reporting an incident to campus officials. For these students, stigma and community-related shame, not having established relationships with reporting officials and feeling like no one would care were barriers to reporting. Furthermore, Luther mentions that gendered expectations are a problem:

As a male, if I were sexually assaulted, I believe that the police would do absolutely nothing. Sexual assault is an offence that is typically committed by a male with a female victim. Therefore, if female victims of sexual assault hardly achieve justice, then my chances of justice are even slimmer.

Some participants mentioned the difficulty of men reporting sexual assault due to the social construction of masculinity. For example, Sam notes:

The problem with reporting is victim-blaming. A lot of men are afraid of reporting because there is a stigma attached to men and masculinity with being strong. Being female changes the dynamic, but the feelings of resistance are similar. Females might fear the possible shame and recidivism of their trauma/experiences by reporting.

These responses reveal structured action in play, with campus officials as actors performing hegemonic constructions of masculinity.

When asked specifically what actions the participants would take if sexual violence were to happen to them, the majority of students said that they would file the complaint with either university authorities, university agents, campus security, or student services. Participants often provided few details beyond this. Some students replied that they would probably not do anything. Overall, the participants did not reveal a plan for filing a complaint. No one mentioned using the telephone number provided by the policy and only Rachel mentioned the email listed on the policy. She stated that she would not use this email because it was just a general email account. This finding suggests that this portion of the policy might be ineffective when it comes to filing a complaint as students were reluctant or did not think to contact the email or telephone number provided.

Participants identified several problems with reporting, including feeling anxious about having to interact with the perpetrator afterward, fearing that they would not be believed or that authorities would minimize the incident. For example, Rachel, who had experience reporting at the university, stated:

I have experienced many problems with reporting at [this university]. This is due to the fact that I had to report a [neighbouring college] student...I ended up dealing only with [the college], and the perpetrator is still showing up in spaces where he knows I will be, despite a no-contact order. I reported this, ... and their 
response was that they can't tell him where to go and where not [to] go because they don't want to limit his movement on campus. This is NOT SURVIVORCENTRIC and is limiting the victim who experienced harm for the comfortability of the perpetrator. If he chooses to show up at another one of my club's events, I do not know what I will do.

Rachel expresses feelings of powerlessness as she experienced delayed wait times, an unprepared point of contact, and an ineffective no-contact order.

Revictimization was an additional barrier to reporting that concerned participants. For example, Vikki notes, "It's my word against theirs, and without a rape kit or a confession from the opposing party, the re-victimization process is likely to happen all over again when you report details of sexual assault, even though reporting it to campus safety." For some, a further feeling of powerlessness exists in fear of reprisal, concern that no intervention would happen with the offender, as well as the threat of harm to reputation, academic career, and physical body. Largely, social constructions of male powerfulness and female powerlessness were present in the student's answers for barriers to reporting.

\section{Policy Recommendations}

The participants provided many recommendations on how to improve campus policy and the safety of students on campus. Their recommendations included ways to make reporting easier while also revealing that the current process is not a fair one. Due to Rachel's experience with reporting, she had many applicable recommendations for improving the policy:

If possible, I would condense these and make them much more explicit. I was able to easily understand this due to my experience and knowledge. However, I feel it is not quickly accessible and understandable for a survivor. Especially one who is looking for immediate help and has experienced extreme harm or suffering as a result of sexual violence. In addition, there should be an appendix with these key terms translated into several other languages to make it accessible for our diverse student population. There is a large portion of [the university's] population whose first language is not English.

Addressing language barriers is an important suggestion since the policy does not address this.

Promoting safe environments for survivors, which helps inhibit victim-blaming, was mentioned by most students as being very important. More specifically, allowing for special accommodations, getting men involved to help create a safe reporting culture on campus, and adding the contact information and links of support services for survivors of sexual violence into the actual policy were all mentioned. Further, Chris notes:

I think [the policies] are well written. The problem for me does not rest in how these...[policies] are defined or prescribed online. The issue is with how effectively they are able to implement such cases in swift and certain manners.... 
manners...You can have it written eloquently and preached ad nauseam, but if one encounters conduct contrary to what had been stated, all efforts become futile and devoid of meaning.

Creating a safe environment on campus requires that post-secondary institutions actively follow through on their written policies.

Encouragingly, almost half the students said that they found the outlined reporting process in the policy supportive. There were a minority of students that stated they found portions of the policy problematic. For example, Tom stated:

The only issue I have is where it says, "case determined on a balance of probabilities," which, while it is not the standard of beyond a reasonable doubt, still casts doubt on the person thinking of reporting before the process has begun, which is a sharp difference from the first sentence which says "you shall be believed." I believe the idea that there is a case to determine how to solve the problem could be presented in a better way, that doesn't imply a shadow of a doubt.

Tom highlights that the language used in the policy is important and that policymakers should scrutinize the policy for areas that might act as a barrier to reporting.

Almost all of the students addressed the need for transparency and simplicity within the policy. Participants suggest using a more simplistic language that still granted access to all the pertinent information in the reporting process. For example, Chris' recommends:

More succinct. It is very lengthy and may lead to people being confused. Those who are reading this would most likely be those who have encountered said incidents. It may be too confusing and loaded. I would try to be more succinct in how I deliver the policies. I know there is a lot to take in, but a shorter delivery would probably be better.

In addition to making the policy more easily understood by students, Hannah recommends inclusivity based on one's identity (e.g., race, gender, sexual orientation, ability) should be noted in the policy to ensure that all individuals feel comfortable and safe enough to seek help and report.

Furthermore, knowing the name of the person that students are to report to is very important to participants. As Rachel states:

I would specify the exact department or individual responsible for receiving disclosures and support. This person should specialize in responding to sexual violence. I would also not emphasize security at the end [of the policy]. This is extremely problematic and does not seem survivor-centric because of the way it reads. It says that security is going to act upon a report or disclosure without 
consent? This would scare me immediately. This does not read as empowering whatsoever. Also, some marginalized communities may not want to be involved with security, therefore discouraging them from reporting as well.

Importantly, Rachel highlights the caveats within the policy that allow the post-secondary institution to act without the survivor's agreement and how these caveats could discourage reporting.

Further recommendations made by a few students included ways to make the policy more accessible every day so that students know how to report intrinsically. This recommendation included integrating the policy into academic life in the same way that academic integrity is into the curriculum. In terms of reducing the fear of rape on campus, students recommended security measures such as brighter city lights, emergency buttons, and increased security officer presence. Participants also suggested activating and increasing programs such as walking students to their cars or around campus. Further, Hannah suggested the importance of "having campaigns and communities that understand what sexual assault is and promote consent."

Similarly, Rachel noted that a change in campus culture to a consent culture through educational means and services was necessary, "I think [the university] should make their actions regarding sexual violence more public. They should have a gender and sexuality centre (a space for cis-women and queer folks), so we have a space where we can feel safe." These suggestions echoed what the other students have recommended that participants wanted a safe environment and transparency with the institution concerning disclosing and reporting sexual violence.

\section{Discussion and Conclusion}

Powerlessness, transparency, and social constructions of masculinity were all highlighted as important issues by participants but were absent from the post-secondary institution's sexual violence policy. Participants were hesitant about the reporting structures in place and were untrusting of campus security. At the same time, they were not able to clearly and effectively define sexual assault, consent, or sexual violence. This inability suggests that either the provided definitions were too complex or that general sexual education needs to be improved so that students have a firm understanding of these terms before entering this high-risk environment. Participants recommended more education on and easier access to information on sexual violence. In particular, they recommended that students be informed of their options and procedures at every stage of the process while still maintaining confidentiality. In what follows, we examine participants' understandings of this post-secondary institution's sexual violence policy through a lens of structured action theory.

Institutional power can help encourage and maintain the under-reporting of sexual violence and an unsafe campus environment for women and LGBTQA. For example, US post-secondary institutions do not disclose true rates of sexual violence to maintain an illusion of safety (Yung, 2015). As the division of labour commences with educational opportunities, an unsafe campus environment could be a deterrent for women wanting to pursue higher education and thereby 
enforcing existing class and gender divisions (Rozee, 2008). Together with the social structures of sexuality and power, victim-blaming and the lack of appropriate resources for traumatized students devalues survivors.

A post-secondary institution can make their power known by setting the agenda both in policy and protocol. In economic, social, political, and cultural terms, the post-secondary institution has the upper hand as they are setting the terms to follow. Given that the institution writes the policy, hires campus security, and expects students to abide by the rules of the institution, the institution can deny a student's authority to make decisions. Also, the institution can deny informing the student on all the steps of a formal and informal complaint process, confidentiality, and protective resources.

The students' recommendations to improve the sexual violence policy at the postsecondary institution reveals their subordinate positions. In particular, these participants highlight the need to create a more easily understood policy for survivors, the need to consider those who do not have English as their first language, and consider students with intersecting oppressions. Furthermore, students do not entirely trust campus security and reporting procedures and are concerned about victim-blaming, community shame, and minimizing their experiences. Most importantly, the students are aware of the policy's statements that campus security could act upon a report or disclosure without consent, noting this is not 'survivor-centric.' This caveat in the policy allows the institution to act without the survivor's agreement or acknowledgment, thereby removing the power to control the process from the victim.

Given that the institution sets the agenda, the policy could be acting as a statement of power with gender, diversity, and equality excluded. The institution does not address language, cultural, and confidentiality sensitivities. There is limited intersectionality seen within the policy. Accordingly, a student's recommendation was to have the inclusivity of one's identity (race, gender, sexual orientation, ability) more clearly written into the policy. Furthermore, there were portions of the policy that were contradictory in that one portion stated that each case was determined on a balance of probabilities, whereas in another portion, it stated that a complainant would be believed. These participant's sentiments are supported by Tamborra and Narchet (2011), who note that many students do not report sexual violence as they feel that campus services will not meet their needs.

Most students said they would file a complaint to university officials, university agents, campus security, or student services, should sexual violence happen to them. We can only assume that they would be doing it in person since no one would be using the listed email or listed telephone number in the policy. No one mentioned a plan, which is surprising as $25 \%$ of postsecondary students will experience sexual assault (Fisher et al., 2000). Furthermore, not understanding the legal definition of sexual assault is a reason for under-reporting (Fisher et al., 2000; Tamborra \& Narchet, 2016; Walsh et al., 2010) and was found to be an issue in our study. We think that students should understand the key definitions of sexual assault, consent, and sexual violence so that fewer survivors doubt the meaning of their victimization.

In summary, participants' understandings and perceptions of campus sexual violence policy reveal several ways to improve campus policies, encourage reporting, and, most importantly, help survivors. First, having a point of contact that students are aware of and can feel comfortable reporting to is important (Tamborra \& Narchet, 2011). Second, campus policies should contain 
language that is inclusive of all students and provide clear definitions of sexual assault, consent, and sexual violence. Policies should also outline the necessary steps and options for reporting (Gunraj et al., 2015; Osborne, 1992). Third, since the campus environment can act as a barrier to reporting, especially in a male-dominated culture and policies that do not provide confidentiality (Brubaker, 2009), those institutional power issues must be addressed in the policy. Any postsecondary institution should be able to provide specifics for when there is confidentiality while at the same time being sensitive to a student's intersecting identities. If this is not possible, then a third-party service might be better at handling sexual assault complaints to avoid any biases. Finally, the inclusion of gender and age prevalence of sexual assault, particularly the highest atrisk group, must be acknowledged by the policy. By ignoring this, the institution is helping to perpetuate the myth that sexual violence exists in a vacuum. Including current statistics in the policy might help those who have experienced sexual violence come forward while at the same time, help students to understand the realities of sexual assault victimization by providing transparency.

Overall, it is important to prevent survivors from experiencing feelings of self-blame, guilt, embarrassment, fear, fear of reprisal (Fisher et al., 2000; Tamborra, \& Narchet, 2011; Walsh et al., 2010). We believe that there needs to be more research on students' understanding of sexual violence policies at post-secondary institutions. In addition to continued research on this topic, we suggest incorporating student feedback on the policy on an annual basis, including the sexual assault policy in student materials, advertising the policy on campus, and educating students on the topic. Our study has only begun to examine this issue. This study's limitations include a small sample size and collecting data at only one post-secondary institution. If we are to make progress on this issue, future research needs to examine further student understandings of campus policy and ways to incorporate these understandings into campus policies. 


\section{References}

Amar, A. F., Strout, T. D., Simpson, S., Cardiello, M., \& Beckford, S. (2014). Administrators' perceptions of college campus protocols, response, and student prevention efforts for sexual assault. Violence and Victims, 29(4), 579. doi:10.1891/0886-6708

Ammar, N., Frederick, T., Marques, O., O’Connor, C. \& Scott, H. (2016). Responding to sexual violence at Ontario post-secondary schools: Recommendations and best practices. The Ministry of Community Safety and Correctional Services of Ontario.

Benedict, H. (2005). The language of rape. In E. Buchwald, P. Fletcher, \& M. Roth (Eds.), Transforming a Rape Culture: Revised Edition (pp.123-128). Minneapolis, MN: Milkweed Editions.

Browne, R. (October 30, 2014). Why don't Canadian universities want to talk about sexual assault? Macleans.ca. Retrieved from: http://www.macleans.ca/education/unirankings/why-dontcanadian-universities-want-to-talk-about-sexual-assault/

Brubaker, S. J. (2009). Sexual assault prevalence, reporting and policies: Comparing college and university campuses and military service academies. Security Journal, 22(1), 56-72. doi:http://dx.doi.org/10.1057/sj.2008.10

Buchwald, E., Fletcher, P., \& Roth, M. (2005a) Preamble. In E. Buchwald, P. Fletcher, \& M. Roth (Eds.), Transforming a Rape Culture: Revised Edition (pp. XI). Minneapolis, MN: Milkweed Editions.

Buchwald, E., Fletcher, P., \& Roth, M. (2005b). Are we living in a rape culture? In E. Buchwald, P. Fletcher, \& M. Roth (Eds.), Transforming a Rape Culture: Revised Edition (pp. 5-9). Minneapolis, MN: Milkweed Editions.

California Sexual Assault Task Force. (2004). California Campus Blueprint to Address Sexual Assault. Sacramento, CA: California Campus Sexual Assault Task Force.

Campbell-Ruggaard, J. \& Van Ryswyk, J. (2001) Rape on campus: Numbers tell less than half the story. In: M. Smith (Ed.) Sex without Consent: Rape and Sexual Coercion in America (283 - 299). New York: New York University Press.

Canadian Women's Foundation (n.d.). The \#Metoo Movement in Canada. Retrieved from: https://canadianwomen.org/the-facts/

Charmaz, K. (2008). Constructionism and the grounded theory method. In J.A. Holstein and J.F. Gubrium (Eds.), Handbook of Constructionist Research. (pp. 397-412). New York: The Guilford Press.

Collins, P. H. (2000). Black feminist thought : Knowledge, consciousness, and the politics of empowerment. New York: Routledge.

Cook, S. G. (2010). Sexual Assault: A matter of civil rights and Title IX. Women in Higher Education, 19(6), 16-17.

DeKeseredy, W., \& Kelly, K. (1993). The incidence and prevalence of woman abuse in Canadian university and college dating relationships. Canadian Journal of Sociology/Cahiers canadiens de sociologie, 137-159.

DeKeseredy, W. S., \& Schwartz, M. D. (1998). Woman abuse on campus: Results from the Canadian national survey. Thousand Oaks: Sage Publications. 
DeKeseredy, W.S., \& Schwartz, M. D., \& Alvi, S. (2000). The role of profeminist men in dealing with woman abuse on the Canadian College Campus. Violence Against Women, 6 (9), 918935.

DeKeseredy, W. S., Schwartz, M. D., \& Tait, K. (1993). Sexual assault and stranger aggression on a Canadian university campus. Sex Roles, 28(5-6), 263-277.

Denzin, N. K. \& Lincoln, Y. S. (2011a). The Sage Handbook of Qualitative Research (4 ${ }^{\text {th }}$ edition). California: Sage Publications.

Denzin, N. K. \& Lincoln, Y.S. (2011b). The discipline and practice of qualitative research. In N. K. Denzin and Y. S. Lincoln (Eds.), The Sage Handbook of Qualitative Research (p.1-21). California: Sage Publications.

Doucet, A., \& Mauthner, N. (2008). What can be known and how? Narrated subjects and the listening guide. Qualitative Research, 8(3), 399-409.

Fisher, B. S., Cullen, F. T., \& Turner, M. G. (2000). The sexual victimization of college women. Washington, DC: National Institute of Justice.

Flyvbjerg, B. (2011). Case study. In N. K. Denzin and Y. S. Lincoln (Eds.), The Sage Handbook of Qualitative Research (p. 301-317). California: Sage Publications.

Gunraj, A., Wandio, C., Metro Action Committee on Public Violence against Women and Children, \& Canadian Electronic Library (Firm). (2015). Sexual assault policies on campus: A discussion paper. Ottawa, Ontario: Canadian Electronic Library.

Iyer, N., McRae, D, Backhouse, C. (2015). Report on the task force on misogyny, sexism and homophobia in Dalhousie university faculty of dentistry. Ottawa: Canadian Electronic Library.

Kincheloe, J. L., McLaren, P. \& Steinberg, S. R. (2011). Critical Pedagogy, and qualitative research: Moving to the bricolage. In N. K. Denzin and Y. S. Lincoln (Eds.), The Sage Handbook of Qualitative Research (p.163-179). California: Sage Publications.

Lancaster, J.M., \& Waryold, D.M. (2008). Student Conduct Practice: The Complete

Guide for Student Affairs Professionals. Sterling, VA: Stylus Publishing.

Messerschmidt, J. W. (1993). Masculinities and Crime: Critique and reconceptualization of theory. Lanham, MD: Rowman \& Littlefield.

Messerschmidt, J. (2000). Nine lives : Adolescent masculinities, the body, and violence. Boulder, Colo.: Westview Press.

Messerschmidt, J. (2016). Masculinities in the making : From the local to the global.

Messerschmidt, J. (2018). Hegemonic Masculinity : Formulation, Reformulation, and Amplification.

Newton-Taylor, B., DeWit, D., \& Gliksman, L. (1998). Prevalence and factors associated with physical and sexual assault of female university students in Ontario. Health Care for Women International, 19(2), 155-164.

Olesen, V. (2011). Feminist qualitative research in the millennium's first decade: Developments, challenges prospects. In N. K. Denzin and Y. S. Lincoln (Eds.), The Sage Handbook of Qualitative Research (p.129-146). California: Sage Publications.

Osborne, R. L. (1992) Sexual Harassment in Universities: A Critical View of the Institutional Response. Canadian Woman Studies, 12(3) 72-76. 
Report of the task force on respect and equality: Ending sexual violence at the University of Ottawa. (2016). Ottawa, ON: University of Ottawa

Rozee, P. D. (2008). Women's fear of rape: Cause, consequences, and coping. In J.C.Chrisler, C. Golden, \& P. D. Rozee (Eds.), Lectures on the psychology of women (pp. 322-337). Boston: McGraw-Hill.

Senn, C. Y., Eliasziw, M., Barata, P. C., Thurston, W. E., Newby-Clark, I. R., Radtke, H. L., Hobden, K. L., \& SARE Study Team. (2014). Sexual violence in the lives of first-year university women in Canada: no improvement in the $21^{\text {st }}$ century. Women's Health, 14, 135-142. Retrieved from: http://www.biomedcentral.com/1472-6874/14/135

Sheehy, E. A. \& Gilbert, D. (August 10, 2015). Responding to Sexual Assault on Campus: What Can Canadian Universities Learn from US Law and Policy. Forthcoming, in Elizabeth Quinlan, Andrea Quinlan, Curtis Fogel \& Gail Taylor (Eds) Sexual Assault on Canadian University and College Campuses (Wilfrid Laurier University Press); Ottawa Faculty of Law Working Paper No. 2015-26. Available at SSRN: http://ssrn.com/abstract=2641844

Silbaugh, K. (2015). Reactive to Proactive: Title IX's unrealized capacity to prevent campus sexual assault. Boston University Law Review, 95, 1049- 1076.

Silbey, S. (2003). Designing qualitative research projects. National Science Foundation, Workshop on Qualitative Methods in Sociology, Arlington, Virginia.

Tamborra, T. L., \& Narchet, F. M. (2011). A university sexual misconduct policy: Prioritizing student victims' voices. Crime Prevention and Community Safety, 13(1), 16-33. doi:10.1057/cpcs.2010.17

UBC investigates Frosh students' pro-rape chant: Chant condoned non-consensual sex with underage girls (Sep. 7, 2013). CBC News. Retrieved from: http://www.cbc.ca/news/canada/british-columbia/ubc-investigates-frosh-students-prorape-chant-1.1699589

U.S. Department of Education, Office for Civil Rights. (2013). Dear Colleague. Washington, DC: Author.

Walsh, W. A., Banyard, V. L., Moynihan, M. M., Ward, S., \& Cohn, E. S. (2010). Disclosure and service use on a college campus after an unwanted sexual experience. Journal of Trauma and Dissociation, 11(2), 134-151.

Yung, C. R. (2015). Concealing campus sexual assault: An empirical examination. Psychology, Public Policy, and Law, 21(1), 1-9. doi: http://dx.doi.org/10.1037/law000003 